\title{
Botulinum Toxin-A use in Paediatric Hypertonia: Canadian Practice Patterns
}

\author{
D. Fehlings, U. Narayanan, J. Andersen, R. Beauchamp, J.W. Gorter, \\ A. Kawamura, G. Kiefer, M. Mason, A. McCormick, R. Mesterman, \\ L. Switzer, J. Watt
}

\begin{abstract}
Background: This study aims to assess current practices of Canadian physicians providing botulinum toxin-A (BoNT-A) treatments for children with hypertonia and to contrast these with international "best practice" recommendations, in order to identify practice variability and opportunities for knowledge translation. Methods: Thirteen Canadian physicians assembled to develop and analyze results of a cross-sectional electronic survey, sent to 50 physicians across Canada. Results: Seventy-eight percent (39/50) of physicians completed the survey. The most frequently identified assessment tools were Gross Motor Function Classification System, Modified Tardieu Scale and neurological examination. Goal-setting tools were infrequently utilized. Common indications for BoNT-A injections and the muscles injected were identified. Significant variability was identified in using BoNT-A for hip displacement associated with hypertonia. The most frequent adverse event reported was localized weakness; 54\% reporting this "occasionally" and $15 \%$ "frequently". Generalized weakness, fatigue, ptosis, diplopia, dysphagia, aspiration, respiratory distress, dysphonia and urinary incontinence were reported rarely or never. For dosage, 52\% identified 16 Units $/ \mathrm{kg}$ body weight of Botox ${ }^{\circledR}$ as maximum. A majority $(64 \%)$ reported a maximum 400 Units for injection at one time. For localization, electrical stimulation and ultrasound were used infrequently (38\% and 19\% respectively). Distraction was the most frequently used pain-management technique (64\%). Conclusions: Canadian physicians generally adhere to international best practices when using BoNT-A to treat paediatric hypertonia. Two knowledgetranslation opportunities were identified: use of individualized goal setting prior to BoNT-A and enhancing localization techniques. Physicians reported a good safety profile of BoNT-A in children.
\end{abstract}

RÉSUMÉ: Utilisation de la toxine botulique A dans l'hypertonie chez l'enfant : modalités de pratique au Canada. Contexte : Le but de cette étude était d'évaluer les pratiques actuelles des médecins Canadiens qui traitent des enfants atteints d'hypertonie au moyen de la toxine botulique A (BoNTA) et de les comparer aux recommandations internationales de pratiques exemplaires afin d'identifier la variabilité dans les pratiques et les possibilités de transfert de connaissances. Méthode : Treize médecins Canadiens se sont réunis afin de d'élaborer et d'analyser les résultats d'une enquête électronique transversale auprès de 50 médecins à travers le Canada. Résultats : Soixante-dix-sept pour cent (39/50) médecins ont complété l'enquête. Les outils d'évaluation les plus fréquemment identifiés étaient le système de classification de la fonction motrice globale (GMFCS), l'échelle modifiée de Tardieu et l'examen neurologique. Les outils pour la définition d'objectifs étaient peu utilisés. Les indications les plus fréquentes des injections de BoNT-A et les muscles ciblés ont été identifiés. Il existe une importante variabilité en ce qui concerne l'utilisation de la BoNT-A pour une luxation de la hanche associée à l'hypertonie. L'incident thérapeutique le plus souvent rapporté était une faiblesse localisée, qui était rapportée « occasionnellement » par 54\% des répondants et «fréquemment » par 15\% d'entre eux. Les symptômes suivants étaient rarement ou jamais rapportés : faiblesse généralisée, fatigue, ptose, diplopie, dysphagie, aspiration, détresse respiratoire, dysphonie et incontinence urinaire. Quant au dosage, $52 \%$ ont indiqué que 16 unités/kg était la dose maximum de Botox ${ }^{\circledR}$ utilisée. La majorité des médecins (64\%) ont rapporté la dose de 400 unités comme étant la dose maximale en un même traitement. La stimulation électrique et l'ultrasonographie étaient rarement utilisées (38\% et 19\% respectivement) pour la localisation. La distraction était la technique de gestion de la douleur la plus fréquemment utilisée (64\%). Conclusions : Les médecins Canadiens adhèrent généralement aux pratiques exemplaires internationales quand ils utilisent la BoNT-A pour traiter l'hypertonie chez l'enfant. Ils pourraient bénéficier d'un transfert de connaissances sur les sujets suivants : la définition d'objectifs individualisés avant le traitement et l'amélioration des techniques de localisation. Les médecins ont rapporté que le profil de sécurité de la BoNT-A chez les enfants était bon.

Can J Neurol Sci. 2012; 39: 508-515

Intramuscular injections of Botulinum Toxin A (BoNT-A) produce a local, reversible neuromuscular blockade causing a reduction in neurologically mediated hypertonia (spasticity or dystonia) ${ }^{1}$. Botulinum toxin-A has been shown to be an effective intervention in the management of upper and lower limb hypertonia in children ${ }^{2}$. Botulinum toxin-A is most often used for children with cerebral palsy (CP) or acquired brain injury.

In 2008, Health Canada issued an advisory cautioning health care providers about potential safety risks of botulinum toxins ${ }^{3}$. The focus of this communication was the potential for distant
From the The Hospital for Sick Children (UN); Holland Bloorview Kids Rehabilitation Hospital (AK, DF); Bloorview Research Institute (LS); Department of Paediatrics, University of Toronto (DF), Toronto; HHS McMaster University (RM, JWG), Hamilton; Oshawa Clinic (MM), Oshawa; Children's Hospital of Eastern Ontario (AMM), Ottawa, Ontario; Glenrose Rehabilitation Hospital (JA, JW), Edmonton; Alberta Children's Hospital (GK), Calgary, Alberta; BC Children's Hospital (RB), Vancouver, BC, Canada.

Received December 14, 2011. Final Revisions Submitted February 9, 2012 Correspondence to: Darcy L Fehlings, Holland Bloorview Kids Rehabilitation Hospital, 150 Kilgour Road, Toronto, Ontario, M4G 1R8, Canada.

Email: dfehlings@hollandbloorview.ca 
Table 1: Physician use of baseline assessment tools

\begin{tabular}{|c|c|c|}
\hline & Assessment Tool & Physicians Reporting Routine Use \%) \\
\hline \multirow[t]{2}{*}{ Hypertonia Subtype } & Neurological Examination & $91 \%$ \\
\hline & Hypertonia Assessment Tool (HAT) & $15 \%$ \\
\hline \multirow[t]{2}{*}{ Hypertonia Severity } & Modified Tardieu Scale (MTS) & $72 \%$ \\
\hline & Modified Ashworth Scale (MAS) & $62 \%$ \\
\hline \multirow{3}{*}{$\begin{array}{l}\text { Passive Range of } \\
\text { Motion }\end{array}$} & MTS without goniometry & $75 \%$ \\
\hline & Goniometry & $38 \%$ \\
\hline & MTS with goniometry & $34 \%$ \\
\hline \multirow[t]{2}{*}{ Overall Function } & Gross Motor Function Classification System (GMFCS) & $88 \%$ \\
\hline & Manual Ability Classification System (MACS) & $28 \%$ \\
\hline $\begin{array}{l}\text { Impact of Hypertonia } \\
\text { on Upper Limb (UL) } \\
\text { Function }\end{array}$ & Informal evaluation & $97 \%$ \\
\hline \multirow{6}{*}{$\begin{array}{l}\text { Impact of Hypertonia } \\
\text { on Lower Limb (LL) } \\
\text { Function }\end{array}$} & (Observational) video gait analysis & $50 \%$ \\
\hline & Gross Motor Function Measure (GMFM) & $40 \%$ \\
\hline & Functional Mobility Scale (FMS) & $37 \%$ \\
\hline & Standardized observational gait scale & $30 \%$ \\
\hline & 3-D instrumented video gait analysis & $24 \%$ \\
\hline & Functional Independence Measure for Children (WeeFIM) & $17 \%$ \\
\hline $\begin{array}{l}\text { Occupational } \\
\text { Performance and } \\
\text { Potential Goals of } \\
\text { BoNT-A Therapy }\end{array}$ & Goal Attainment Scale (GAS) & $28 \%$ \\
\hline
\end{tabular}

Tests used $<10 \%$ of the time included: Australian Spasticity Assessment Scale (ASAS), Barry Albright Dystonia (BAD], Quality of Upper Extremities Skills Test (QUEST) Assisting Hand Assessment (AHA), 3-D instrumented motion analysis, Melbourne Assessment of Upper Limb Function (MAULF), Paediatric Evaluation of Disability Inventory (PEDI), Canadian Occupational Performance Measure (COPM)

toxin spread in children with neurologic conditions such as $\mathrm{CP}$. Associated with these warnings, physicians have sought information related to BoNT-A in children such as dosing, types and frequency of side effects and methods of localizing muscles for injections.

Two international consensus statements and a European consensus statement representing "best practice" have recently been published to guide physicians on the practical use of BoNT$\mathrm{A}$ in children with hypertonia ${ }^{4-6}$. Recommendations were provided based on a systematic review of available evidence and expert opinion. The aim of this study is to assess current practices of Canadian physicians providing BoNT-A treatments for children with hypertonia in relation to these "best practice" recommendations. We aim to identify areas where there is variability in Canadian practice and identify areas for knowledge translation activities related to BoNT-A use in children/youth. The overall goal of the project is to optimize the use of BoNT-A as an adjunctive therapy within comprehensive rehabilitation programs for Canadian children with hypertonia.

\section{Methods}

\section{Physician Panel}

A panel of 13 Canadian physicians was formed, comprised of neurologists, physiatrists, orthopedic surgeons and developmental paediatricians who use BoNT-A in paediatric hypertonia. The panel developed content for an electronic survey of Canadian physicians' practices regarding BoNT-A use for childhood hypertonia, and subsequently interpreted the results of survey to understand the state of current practices and identify opportunities for future knowledge translation efforts when current practice deviated from international best practice.

\section{Study Design and Participant Selection}

This is a cross-sectional survey of Canadian physicians who currently administer BoNT-A to children with hypertonia. Ethics approval was obtained from Holland Bloorview Kids Rehabilitation Hospital Research Ethics Board. The goal was to identify and survey all Canadian physicians known to be using BoNT-A for children with hypertonia. Physicians were recruited using a partial snowball approach whereby members of the Canadian Physician Panel identified eligible local physicians in their respective regions of practice.

\section{Data Collection}

Using the international consensus statements as a foundation, the panel developed an electronic survey with a series of questions pertaining to physician demographics, hypertonia assessment, indications for BoNT-A use, BoNT-A safety, injection protocols including dosage and pain management, muscle localization techniques and adjunctive interventions. Fifty Canadian physicians were emailed this one-time anonymous survey, which remained online from April-June 2011. 


\section{Data Analysis}

Aggregate data were analyzed using descriptive statistics and plots of frequencies, means, and standard deviations.

The indications were reported across the International Classification of Functioning, Disability and Health (ICF) domains of body function and structure and activity and participation ${ }^{7}$.

\section{RESUlts}

\section{Respondent Demographics}

Seventy-eight percent (39/50) of physicians who received the survey responded from British Columbia (6), Alberta (7), Saskatchewan (3), Manitoba (1), Ontario (16), Quebec (2), Nova Scotia (2) and New Brunswick (2). The majority of respondents indicated they practice in a rehabilitation/children's treatment center. Subspecialty areas included physiatry, developmental paediatrics, orthopedics, and paediatric neurology. All treat children/youth aged between 1 to 19 years.

\section{Assessment}

Current use of assessment tools for paediatric hypertonia is summarized in Table 1.

\section{Indications}

The results of typical muscles injected (top three muscles per indication) for eight upper limb indications appear in Table 2 and for 13 lower limb indications appear in Table 3. There was variability in current practices using BoNT-A in children with spastic CP and hip subluxation: $41 \%$ of respondents do not inject for this indication, while $32 \%$ inject only if the child is losing range of hip abduction. A minority (21\%) indicated they inject hypertonic muscles in the hip area regularly until there is clear progression of hip subluxation.

\section{Safety}

The perceived frequency of adverse events (AEs) is presented in Table 4 and the perceived severity of the AEs is summarized in Figure 1. Following injection, one child required

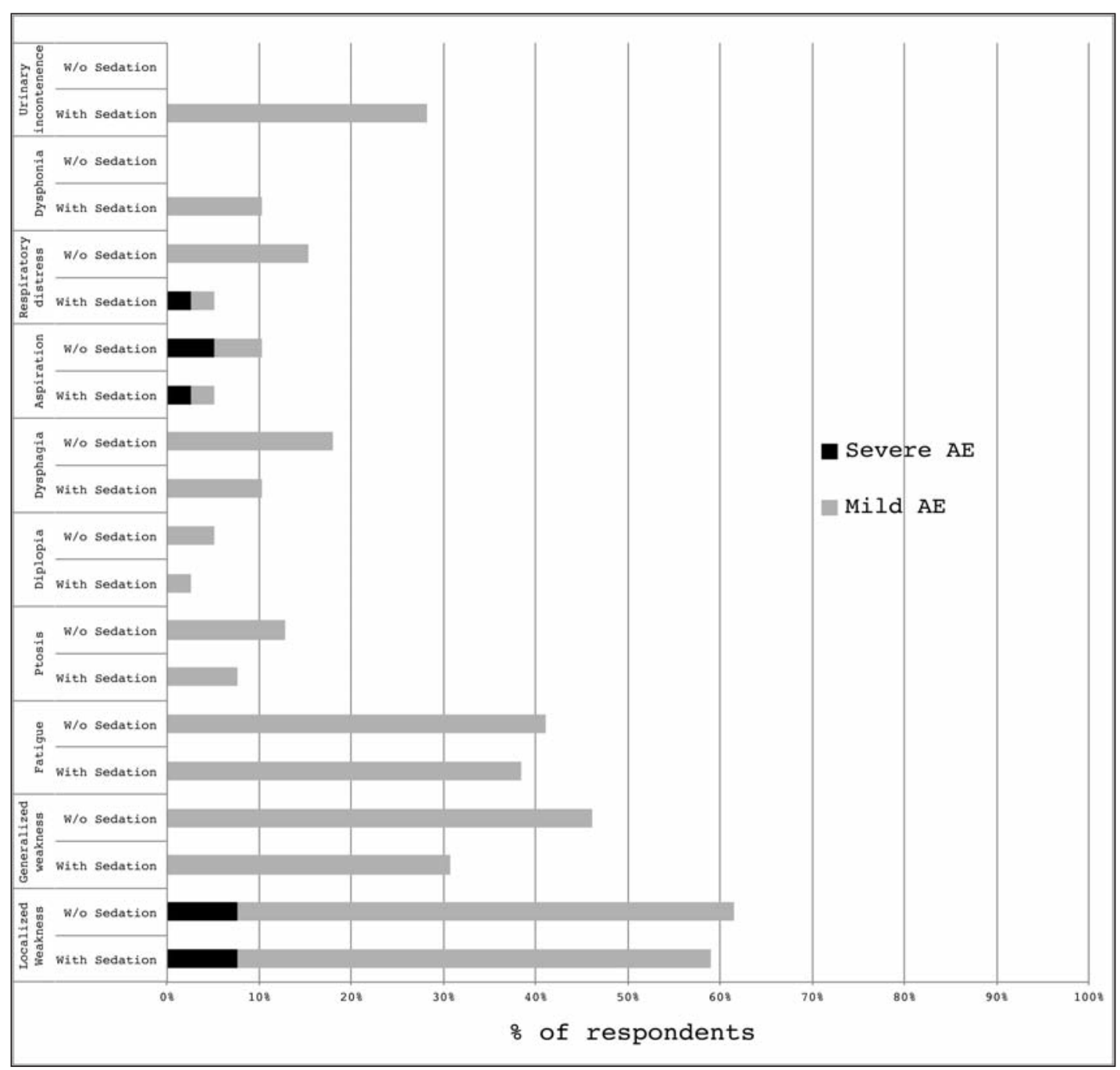

Figure 1: Perceived severity of adverse events post BoNT-A injections 


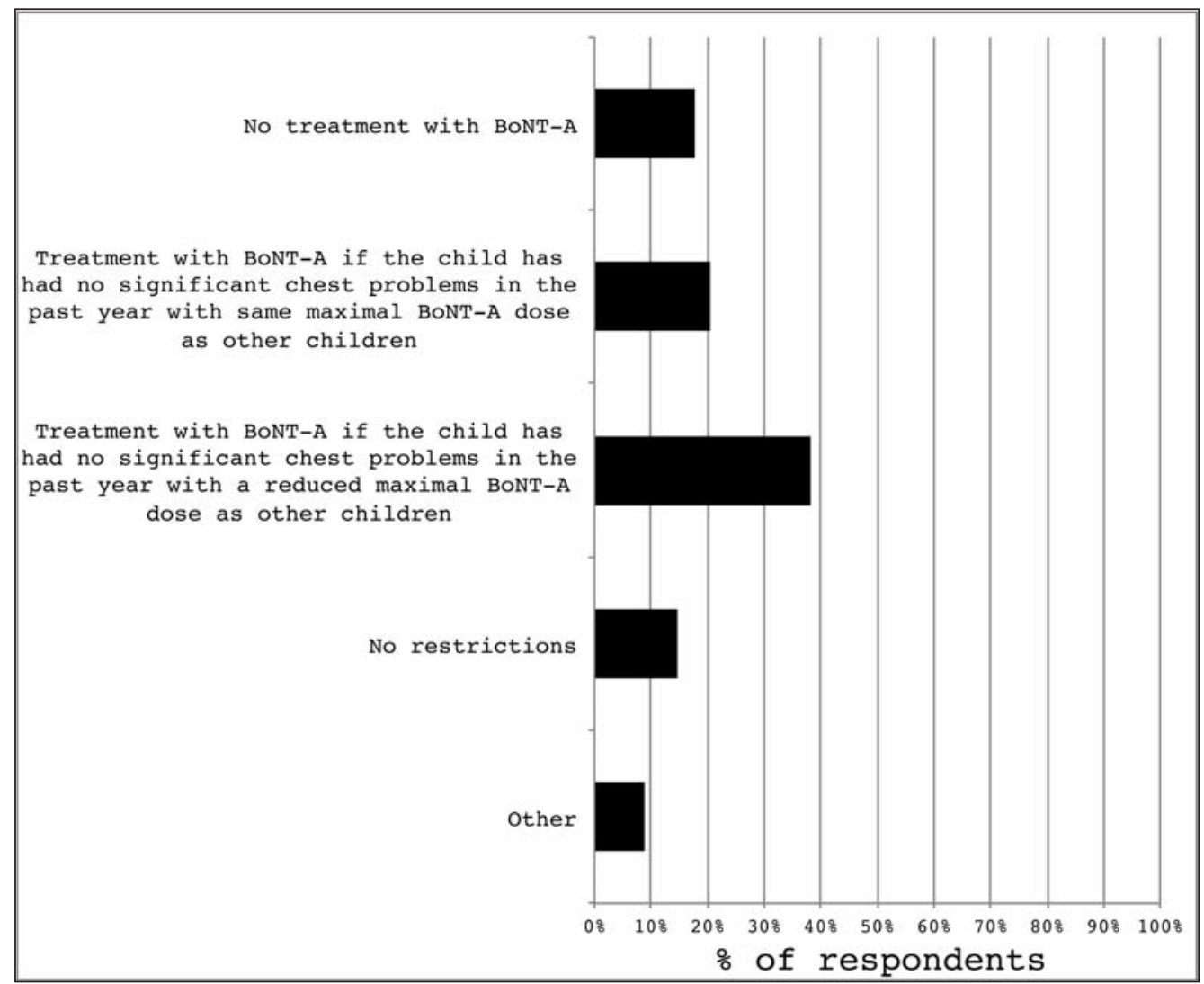

Figure 2: BoNT-A treatment options for children classified at GMFCS level V

hospitalization for aspiration. Three deaths were reported; one due to aspiration following surgery, and two that were interpreted to be associated with co-morbid medical conditions, not BoNT-A.

Seventy-five percent of physicians indicated they routinely obtain written informed consent about the potential risks of BoNT-A. When asked about AE monitoring, 59\% reported that families self-report concerns, while $18 \%$ indicated that their clinics have implemented post-injection AE monitoring programs. Ninety-four percent of clinics give verbal information on adverse events, while $71 \%$ also distribute written information at the time of injection.

\section{Injection Protocol}

All respondents reported using onabotulinumtoxin A (Botox $\left.{ }^{\circledR}\right)$ and $6 \% \quad(n=2)$ reported experience with incobotulinumtoxin A (Xeomin $\left.{ }^{\circledR}\right)$. Due to infrequent use of incobotulinumtoxin $\mathrm{A}$, the remainder of the injection protocol refers to onabotulinumtoxin $A$ (Botox $\AA$ ).

Fifty-two percent of physicians identified 16 Units/kg body weight of Botox ${ }^{\circledR}$ as the maximum amount injected. Thirty percent reported their maximum range between 6 to 12 Units $/ \mathrm{kg}$ body weight, while $18 \%$ injected a maximum dosage of 20 Units/kg body weight. A majority (64\%) reported a maximum 400 Units for injection at any one time; however $9 \%$ of physicians went over 800 Units. Dose per muscle calculations were based on both body weight and total dose per muscle considerations for $85 \%$ of physicians.

Regarding dilution with normal saline, $79 \%$ reported using 2 $\mathrm{ml}(50 \mathrm{Units} / \mathrm{ml})$ for lower limb injections. However, dilution for upper limb injections was more variable with $49 \%$ using $1 \mathrm{ml}$ (100 Units/ml), and 36\% using $2 \mathrm{ml}$ (50 Units $/ \mathrm{ml})$.

Although three to five months was typically considered an appropriate re-injection interval by $74 \%$ of respondents, $30 \%$ favoured waiting six months or longer. Over $80 \%$ considered return of hypertonia or a clear treatment goal in determining reinjection timelines.

Management strategies vary for children with dystonia versus spasticity. Fifty-nine percent considered injecting agonist/ antagonist muscle pairs in children with dystonia. There was no clear consensus on the use of BoNT-A in children/youth who are Gross Motor Function Classification System (GMFCS) Level V as indicated in Figure 2.

\section{Localization Technique}

All participants indicated routine use of palpation/anatomic knowledge, whereas electromyography (EMG), electrical stimulation (e-stim), and ultrasound are routinely used by $49 \%$, $38 \%$, and $19 \%$ of respondents respectively. For upper limb muscle localization, palpation/anatomic knowledge is the most frequently used localization technique except in the flexor digitorum profundus/superficialis and flexor pollicis longus 
muscles where e-stim is more frequently used. For lower limb muscle localization, palpation/anatomic knowledge is also used routinely except for the tibialis posterior, flexor digitorium longus, and flexor hallucis longus where e-stim is more frequently used.

\section{Pain Management During Injections}

Distraction is the most frequently used pain management technique, used by $64 \%$ of responders, followed by EMLA (lidocaine cream) or general anesthetic with $21 \%$ of respondents. Use of sedation, music therapists, or childlife workers is relatively rare.

\section{Adjunctive Interventions}

The most commonly used adjunctive interventions are summarized in Table 2 and 3.

\section{Follow-up Care}

Seventy percent of participants see patients for short-term assessment following BoNT-A injections, scheduled anywhere from two weeks to three months post injection. Respondents indicated that the post-injection follow-up assessment was conducted by the clinic physician $(68 \%)$, clinic occupational therapist $(55 \%)$, clinic physiotherapist $(84 \%)$ or clinic nurse $(23 \%)$. The majority $(82 \%)$ of respondents indicated they could transition teens to an adult BoNT-A clinic once they reached 19 years.

\section{DiscuSSION}

The 50 physicians identified to receive the survey are likely to represent nearly all Canadian physicians known to be using BoNT-A for children with hypertonia. The $78 \%$ survey response rate is therefore adequate to provide generalizable results that reflect current Canadian practices.

\section{Assessment}

Canadian clinicians are following international consensus "expert opinion" recommendations in their routine use of the Modified Tardieu Scale to assess hypertonia severity and passive range of motion and the GMFCS to establish overall gross motor function. The Manual Ability Classification System (MACS), assessing bimanual ability to handle objects, was not frequently used. Formal measures assessing the impact of hypertonia on upper and lower extremity function are not routinely used, perhaps reflecting the time required for these assessments and the need for additional team members (e.g. therapist) to complete

Table 2: Muscles most frequently injected (top 3) and adjunctive interventions (top 2) for upper limb (UL) indications

\begin{tabular}{|c|c|c|}
\hline INDICATION & Top 3 UL muscles injected & $\begin{array}{l}\text { Adjunctive Interventions } \\
\text { (Top } 2 \text { identified for each intervention) }\end{array}$ \\
\hline \multicolumn{3}{|l|}{ Body Structure / Function } \\
\hline Relieve muscle spasms & $\begin{array}{l}\text { Trapezius }(67 \%) \\
\text { Triceps brachii }(58 \%) \\
\text { Extensor digitorum communis }(56 \%)\end{array}$ & $\begin{array}{l}\text { Stretching (83\%) } \\
\text { Thermoplastic splinting (57\%) }\end{array}$ \\
\hline Pain management & $\begin{array}{l}\text { Pectoralis major }(44 \%) \\
\text { Trapezius }(44 \%) \\
\text { Triceps brachii }(42 \%)\end{array}$ & $\begin{array}{l}\text { Stretching }(67 \%) \\
\text { Thermoplastic splinting (48\%) }\end{array}$ \\
\hline Improve thumb position & $\begin{array}{l}\text { Flexor pollicis longus }(100 \%) \\
\text { Flexor pollicis brevis/Opponens pollicis }(100 \%) \\
\text { Adductor pollicis }(94 \%)\end{array}$ & $\begin{array}{l}\text { Other splints ( } 70 \%) \\
\text { Thermoplastic splinting (48\%) }\end{array}$ \\
\hline Elbow flexion & $\begin{array}{l}\text { Brachioradialis }(97 \%) \\
\text { Brachialis }(93 \%) \\
\text { Biceps brachii }(91 \%)\end{array}$ & $\begin{array}{l}\text { Stretching }(80 \%) \\
\text { Thermoplastic splinting }(70 \%)\end{array}$ \\
\hline Wrist flexion & $\begin{array}{l}\text { Flexor carpi radialis }(100 \%) \\
\text { Flexor carpi ulnaris }(97 \%) \\
\text { Flexor digitorum profundis }(64 \%) \\
\text { Flexor digitorum superficialis }(64 \%)\end{array}$ & $\begin{array}{l}\text { Thermoplastic splinting }(87 \%) \\
\text { Stretching }(77 \%)\end{array}$ \\
\hline \multicolumn{3}{|l|}{ Activity / Participation } \\
\hline $\begin{array}{l}\text { Reduce tone to facilitate } \\
\text { ease of dressing }\end{array}$ & $\begin{array}{l}\text { Pectoralis major }(100 \%) \\
\text { Brachioradialis }(83 \%) \\
\text { Teres major }(79 \%) \\
\text { Biceps brachii }(79 \%)\end{array}$ & $\begin{array}{l}\text { Stretching }(83 \%) \\
\text { Other splints }(60 \%)\end{array}$ \\
\hline $\begin{array}{l}\text { Improve cosmetic } \\
\text { appearance of the hand/arm }\end{array}$ & $\begin{array}{l}\text { Extensor digitorum communis }(75 \%) \\
\text { Flexor carpi radialis }(71 \%) \\
\text { Flexor carpi ulnaris }(68 \%)\end{array}$ & $\begin{array}{l}\text { Thermoplastic splinting }(54 \%) \\
\text { Stretching }(50 \%)\end{array}$ \\
\hline $\begin{array}{l}\text { Improve the use of hand in } \\
\text { daily activities }\end{array}$ & $\begin{array}{l}\text { Pronator quadratus }(100 \%) \\
\text { Adductor pollicis }(97 \%) \\
\text { Pronator teres }(97 \%)\end{array}$ & $\begin{array}{l}\text { Stretching }(71 \%) \\
\text { Thermoplastic splinting }(71 \%)\end{array}$ \\
\hline
\end{tabular}


Table 3: Muscles most frequently injected (top 3) and adjunctive interventions (top 2) for lower limb (LL) indications

\begin{tabular}{|c|c|c|}
\hline INDICATION & Top 3 LL muscles injected & $\begin{array}{l}\text { Adjunctive Interventions (Top } 2 \\
\text { identified for each intervention) }\end{array}$ \\
\hline \multicolumn{3}{|l|}{ Body Structure / Function } \\
\hline Minimize loss of muscle length & $\begin{array}{l}\text { Medial hamstrings (semimembranosus) }(72 \%) \\
\text { Medial hamstrings (semitendinosus) }(71 \%) \\
\text { Gastrocnemius }(71 \%)\end{array}$ & $\begin{array}{l}\text { Stretching }(90 \%) \\
\text { Thermoplastic splinting }(77 \%)\end{array}$ \\
\hline Relieve muscle spasms & $\begin{array}{l}\text { Adductor longus }(61 \%) \\
\text { Adductor magnus }(52 \%) \\
\text { Rectus femoris }(50 \%)\end{array}$ & $\begin{array}{l}\text { Stretching }(83 \%) \\
\text { Thermoplastic splinting }(37 \%)\end{array}$ \\
\hline Pain management & $\begin{array}{l}\text { Iliopsoas }(60 \%) \\
\text { Adductor longus }(58 \%) \\
\text { Adductor magnus }(57 \%) \\
\end{array}$ & $\begin{array}{l}\text { Stretching }(79 \%) \\
\text { Thermoplastic splinting }(37 \%)\end{array}$ \\
\hline Hip subluxation & $\begin{array}{l}\text { Adductor longus }(67 \%) \\
\text { Adductor magnus }(56 \%) \\
\text { Gracilis }(50 \%)\end{array}$ & $\begin{array}{l}\text { Stretching }(63 \%) \\
\text { Other splints }(74 \%)\end{array}$ \\
\hline Ankle plantar flexion & $\begin{array}{l}\text { Gastrocnemius }(97 \%) \\
\text { Soleus }(94 \%) \\
\text { Peroneus longus/brevis }(88 \%)\end{array}$ & $\begin{array}{l}\text { Stretching }(94 \%) \\
\text { Other splints }(74 \%)\end{array}$ \\
\hline \multicolumn{3}{|l|}{ Activity / Participation } \\
\hline $\begin{array}{l}\text { Reduce tone to facilitate ease of } \\
\text { dressing }\end{array}$ & $\begin{array}{l}\text { Adductor magnus }(78 \%) \\
\text { Adductor longus }(73 \%) \\
\text { Gracilis }(63 \%)\end{array}$ & $\begin{array}{l}\text { Stretching }(84 \%) \\
\text { Other splints }(53 \%)\end{array}$ \\
\hline Reduce tone to facilitate hygiene & $\begin{array}{l}\text { Adductor magnus }(96 \%) \\
\text { Adductor longus }(82 \%) \\
\text { Gracilis }(67 \%)\end{array}$ & $\begin{array}{l}\text { Stretching }(88 \%) \\
\text { Other splints }(47 \%)\end{array}$ \\
\hline $\begin{array}{l}\text { Improve/maintain 'gait' in child with } \\
\text { unilateral spastic CP GMFCS I, II }\end{array}$ & $\begin{array}{l}\text { Gastrocnemius }(97 \%) \\
\text { Soleus }(97 \%) \\
\text { Tibialis posterior }(91 \%)\end{array}$ & $\begin{array}{l}\text { Thermoplastic splinting }(94 \%) \\
\text { Stretching }(91 \%)\end{array}$ \\
\hline $\begin{array}{l}\text { Improve/maintain ability to transfer in } \\
\text { child with CP GMFCS IV }\end{array}$ & $\begin{array}{l}\text { Medial hamstrings (semitendinosus) }(87 \%) \\
\text { Medial hamstrings (semimembranosus) }(84 \%) \\
\text { Adductor magnus }(81 \%)\end{array}$ & $\begin{array}{l}\text { Stretching }(84 \%) \\
\text { Thermoplastic splinting }(84 \%)\end{array}$ \\
\hline $\begin{array}{l}\text { Improve/maintain ability to use a } \\
\text { stander or walker for child with CP } \\
\text { GMFCS IV }\end{array}$ & $\begin{array}{l}\text { Gastrocnemius }(91 \%) \\
\text { Medial hamstrings (semitendinosus) }(87 \%) \\
\text { Medial hamstrings (semimembranosus) }(87 \%) \\
\text { Iliopsoas }(86 \%)\end{array}$ & $\begin{array}{l}\text { Thermoplastic splinting }(87 \%) \\
\text { Stretching }(80 \%)\end{array}$ \\
\hline
\end{tabular}

Table 4: Physician identified perceived frequency of adverse events following BoNT-A injections with and without sedation

\begin{tabular}{l|c|c|c|c}
\hline & Never & Rarely < $\%$ & $\begin{array}{l}\text { Occasionally } \\
\mathbf{1 - 9 \%}\end{array}$ & Frequently $>\mathbf{1 0 \%}$ \\
\hline Localized weakness & $7 \%$ & $23-24 \%$ & $\mathbf{5 4 - 5 5 \%}$ & $14-15 \%$ \\
\hline Generalized weakness & $43-48 \%$ & $\mathbf{5 2 - 5 7 \%}$ & $0-7 \%$ & $0 \%$ \\
\hline Fatigue & $40-41 \%$ & $\mathbf{4 7 - 5 2 \%}$ & $7-13 \%$ & $0 \%$ \\
\hline Ptosis & $\mathbf{8 5 - 8 9 \%}$ & $11-15 \%$ & $0 \%$ & $0 \%$ \\
\hline Diplopia & $\mathbf{9 6 - 9 7 \%}$ & $3-4 \%$ & $0 \%$ & $0 \%$ \\
\hline Dysphagia & $\mathbf{7 8 - 8 0 \%}$ & $17-22 \%$ & $0-3 \%$ & $0 \%$ \\
\hline Aspiration & $\mathbf{8 9 - 9 3 \%}$ & $3-11 \%$ & $0-3 \%$ & $0 \%$ \\
\hline Respiratory distress & $\mathbf{8 6 - 9 7 \%}$ & $3-14 \%$ & $0 \%$ & $0 \%$ \\
\hline Dysphonia & $\mathbf{8 5 - 9 0 \%}$ & $10-15 \%$ & $0 \%$ & $0 \%$ \\
\hline Urinary incontinence & $\mathbf{5 8 - 6 3 \%}$ & $33-39 \%$ & $3-4 \%$ & 0 \\
\hline
\end{tabular}

$\%$ in cells refers to $\%$ of physicians responding in each category 
them. Less than one third are routinely using tools to establish goals for BoNT-A intervention. Contrary to the consensus guidelines, half of the respondents are not routinely using a standard observation of gait in ambulatory children. Recommendations from the panel include routine use of the MACS to classify upper extremity function in children receiving BoNT-A, use of tools such as the Canadian Occupational Performance Measure (COPM) or the Goal Attainment Scale (GAS) to align the expectations of the physician, therapist and child/youth and family in response to treatment, as well as to measure change post BoNT-A treatment, and use of a standardized gait assessment tool for ambulatory children (GMFCS I - III).

\section{Indications}

The collection of data that pairs indications for BoNT-A with muscles commonly injected is unique to this survey and creates a useful reference for physicians planning injections. Indications for BoNT-A spanned the ICF framework focused on body structure, function and activity ${ }^{7}$. No specific indications at the ICF participation level or quality of life were identified in this survey, although goals such as facilitating ease of dressing and relief of pain can be seen as ways to optimize well being of the child, and to facilitate caregiving. To standardize indications for BoNT-A injections in Canada, the panel recommends development of a common language and coding system based on a core set of ICF items on body function, body structure and activities/participation level.

\section{Safety}

The survey results confirm numerous previous studies and consensus that injection of BoNT-A in children with cerebral palsy is generally safe ${ }^{8-15}$. Transient mild systemic adverse events, including generalized weakness, fatigue, ptosis, diplopia, dysphagia, aspiration, respiratory distress, dysphonia and temporary urinary incontinence may occur rarely in children after injection, especially in children with more physical limitations (GMFCS IV-V) ${ }^{8-13}$. In our survey, localized weakness close to the injection site, was the most frequently identified adverse event, estimated to occur occasionally (1-9\%). Most adverse events in our survey were identified as mild; however localized weakness and aspiration/respiratory distress were classified as severe less than $10 \%$ of the time. The panel is in agreement with O'Flaherty et al. that there is insufficient evidence to warrant restriction of the administration of BoNT-A in children with cerebral palsy at any GMFCS level, based solely on concerns regarding adverse events ${ }^{14,15}$. As recommended by Naidu et al., upper dose limits should be reviewed for children at all GMFCS levels, particularly those at levels IV and V with a history of aspiration and respiratory disease ${ }^{12}$. In these children, alternatives to general anaesthesia may be particularly important. The long-term consequence of repeated BoNT-A injections on muscle morphology in growing children with cerebral palsy is unknown and was not addressed in this study ${ }^{16-19}$. The panel recommends routinely providing standardized verbal and written parental information about possible adverse events of BoNT-A prior to obtaining informed written consent for all injections. An adverse event monitoring program should be implemented. Botulinum toxin-A should be part of the medication reconciliation process of children with $\mathrm{CP}^{20}$. The National Health Protections Branch adverse events reporting should be utilized by physicians for serious or unexpected adverse events related to BoNT-A injections. Long-term effects of repeated use of BoNT-A on muscle in children requires further study.

\section{Injection Protocol}

In paediatric patients, the majority of physicians restricted the maximal dosage to 16 Units/kg body weight or 400 Units total dosage during a single treatment session. With new concerns about rare but clinically significant distant spread (e.g. generalized weakness), there have been questions about injecting children who have a more severe physical disability (GMFCS V). The lack of consistency in the survey responses reflect this uncertainty, however the most frequent pattern identified was continued usage of BoNT-A in children with GMFCS $\mathrm{V}$ at a reduced maximal dosage as long they did not have a history of chest problems in the preceding 12 months.

\section{Localization Techniques}

The international consensus statements ${ }^{4-6}$ recommend the use of injection techniques that allow the proper identification of the target muscle. This recommendation was based on "expert opinion". Although evidence suggests that e-stim and ultrasound are superior to muscle palpation in the accuracy of needle placement in target muscles, there is insufficient evidence that either method results in superior clinical efficacy ${ }^{21,22}$. It is not surprising that respondents reported ultrasound as the least frequently used method of localization as it was only recently introduced in Canada for this application.

\section{Pain Management}

The wide variation of pain management techniques is most likely explained by resource access disparities between different clinics. While distraction techniques can be incorporated in any clinic setting, specialized support such as child life workers/ trained nurses or the use of sedation and the support of anesthesiologists may only be available in tertiary centers. The variation in practice patterns suggests this may be an area that requires further study and advocacy around resources.

\section{Adjunctive Interventions and Follow-Up Care}

Following BoNT-A injections in the upper extremity, stretching and use of splints were the most common adjunctive treatments utilized. In the lower extremity, strengthening and serial casting were also frequently endorsed. Variability in practice was identified. This is understandable given the lack of evidence regarding the efficacy and optimum delivery of these interventions. In the absence of evidence-informed treatment protocols, the panel suggests that practitioners monitor and measure each patient's response in order to individualize adjunctive interventions following BoNT-A injections.

\section{Follow-Up Care}

The panel recognizes that workload may preclude routine early review by many injecting practitioners. However, early physician review should occur in the setting of adverse events and treatment failures. 
Most paediatric injectors identified that they are able to refer to an adult clinic, but the panel raises the concern that a significant number, $21 \%$, cannot. Transition from paediatric to adult health care providers, including hypertonicity management, should be included in regional health care service planning.

\section{Conclusion}

Overall, Canadian physicians are adhering to current international best practices when using BoNT-A to treat paediatric hypertonia. Opportunities for enhanced practice when compared with the international consensus guidelines were identified in the following areas: the use of individualized goal setting prior to initiating BoNT-A, and enhanced usage of localization techniques. It is interesting to note that both of these international recommendations are based on expert opinion rather than being informed by evidence. This survey provides a useful frame of reference for current dosing practice, muscles commonly injected for different indications, and perceived frequency of adverse events. Areas of advocacy for enhanced resources or services were identified for procedural pain management and adult hypertonia clinics. Further research is recommended in the use of localization techniques for injection, the use of standardized goal setting prior to BoNT-A injections, evaluation of the long-term impact of BoNT-A on muscle morphology, the use of BoNT-A for hip subluxation, and the impact on activity, participation and quality of life.

\section{ACKNOWLEDGEMENTS}

This study was funded by an unrestricted grant received from Allergan. No authors were provided with any funds to participate in the project. Funds were solely used for independent project management and editing. Allergan had no access to the survey or manuscript and had no right of scientific veto. The authors thank Lindsay Craik and Jason Flowerday for assistance in manuscript preparation and editing.

\section{REFERENCES}

1. Jankovic J, Brin MF. Therapeutic uses of botulinum toxin. N Engl J Med. 1991;25(324)(17):1186-94

2. Delgado M, Hirtz D, Aisen $M$, et al. Practice parameter: Pharmacologic treatment of spasticity in children and adolescents with cerebral palsy (an evidence-based review): report of the quality standards subcommittee of the American Academy of Neurology and the practice committee of the Child Neurology Society. Neurology. 2010;74(4):336-43.

3. Health Canada [Internet]. Ottawa: Information Update; Health Canada reviewing issue of distant toxin spread potentially associated with Botox and Botox Cosmetic; [about 3 screens]. [updated 2008 Feb 20; cited 2011 Aug 8]. Available from: http://www.hc-sc.gc.ca/ahc-asc/media/advisoriesavis/_2008/2008_32-eng.php

4. Fehlings D, Novak I, Berweck S, Hoare B, Stott N, Russo R. Botulinum toxin assessment, intervention and follow-up for paediatric upper limb hypertonicity: international consensus statement. Eur J Neurol. 2010;17:38-56.
5. Love SC, Novak I, Kentish M, et al. Botulinum toxin assessment, intervention and after-care for lower limb spasticity in children with cerebral palsy: international consensus statement. Eur J Neurol. 2010;17(Suppl 2):9-37.

6. Heinen F, Desloovere K, Schroeder AS, et al. The updated European consensus 2009 on the use of botulinum toxin for children with cerebral palsy. Eur J Paediatr Neurol. 2010;14(1): 45-66. Epub Nov 14, 2009.

7. World Health Organization. International Classification of Functioning, Disability and Health (ICF). Geneva: World Health Organization, 2001.

8. Naumann M, Albanese A, Heinen F, Molenaers G, Relja M. Safety and efficacy of botulinum type A following long-term use. Eur J Neurol. 2006;13(Suppl 4):35-40.

9. Goldstein FM. Safety of high-dose botulinum toxin type A therapy for the treatment of pediatric spasticity. J Child Neurol. 2006;21: 289-92.

10. Pascual-Pascual SI, Pascual-Castroviejo I. Safety of botulinum toxin type A in children younger than 2 years. Eur J Pediatr Neurol. 2009; 13:511-15.

11. Albavera-Hernandez C, Rodriguez JM, Idrovo AJ. Safety of botulinum toxin A among children with spascity secondary to cerebral palsy: systematic review of randomized clinical trials. Clin Rehabil. 2009;23:394-407.

12. Naidu K, Smith K, Sheedy M, Adair B, Yu X, Graham K. Systemic adverse events following botulinum toxin A therapy in children with cerebral palsy. Dev Med Child Neurol. 2010;52:139-44.

13. Kolaski K, Ajizian S J, Passmore L, Pasutharnchat N, Koman LA, Smith BP. Safety profile of multilevel chemical denervation procedures using phenol or botulinum toxin or both in a pediatric population. Am J Phys Med Rehabil. 2008;87(7):556-66.

14. O'Flaherty S J, Janakan V, Morrow AM, Scheinberg AN, Waugh M-C A. Adverse events and health status following botulinum toxin A injections in children with cerebral palsy. Dev Med Child Neurol. 2011;53:125-30.

15. Narayanan UG. Botulinum toxin: does the black box warning justify change in practice? Dev Med Child Neurol. 2011;53:101-2.

16. Schroeder AS, Ertl-Wagner B, Britsch S, et al. Muscle biopsy substantiates long-term MRI alterations one year after a single dose of botulinum toxin injected into the lateral gastrocnemius muscle of healthy volunteers. Mov Disord. 2009;24:1494-503.

17. Albusaini A, Crosbie J, Shepherd R, Daean C, Scheinberg A. No change in muscle passive stiffness following botulinum toxin injection in children with cerebral palsy. Dev Med Child Neurol. 2011:53:543-8.

18. Schroeder AS, Koerte I, Berweck S, Ertl-Wagner, Heinen F. How doctors think and treat with botulinum toxin. Letter to the editor. Dev Med Child Neurol. 2010;52:875-6.

19. Barrett RS. What are the long-term consequences of botulinum toxin injections in spastic cerebral palsy? Dev Med Child Neurol. 2011;53:485.

20. Bedard P, Tardif L, Ferland A, et al. A medication reconciliation form and its impact on the medical record in a paediatric hospital. J Eval Clin Pract. 2009;17:222-7.

21. Chin TY, Nattrass GR, Selber P, Graham HK. Accuracy of intramuscular injection of botulinum toxin $\mathrm{A}$ in juvenile cerebral palsy: a comparison between needle placement and placement guided by electrical stimulation. J Pediatr Orthop. 2005;25: 286-91.

22. Yang EJ, Rha D-W, Yoo JK, Park ES. Accuracy of needle placement for gastrocnemius muscle in children with cerebral palsy checked against ultrasonography. Arch Phys Med Rehabil. $2009 ; 90: 741-4$. 